\title{
Analisis Perpindahan Moda dari Sepeda Motor dan Mobil Pribadi ke Angkutan Umum di Stasiun Madiun
}

\author{
Arinda Leliana $^{1}$, Hera Widyastuti ${ }^{1}$ \\ Jurusan Teknik Sipil, Institut Teknologi Sepuluh Nopember, Surabaya ${ }^{1}$ \\ Koresponden*, Email: arindaleliana21@gmail.com
}

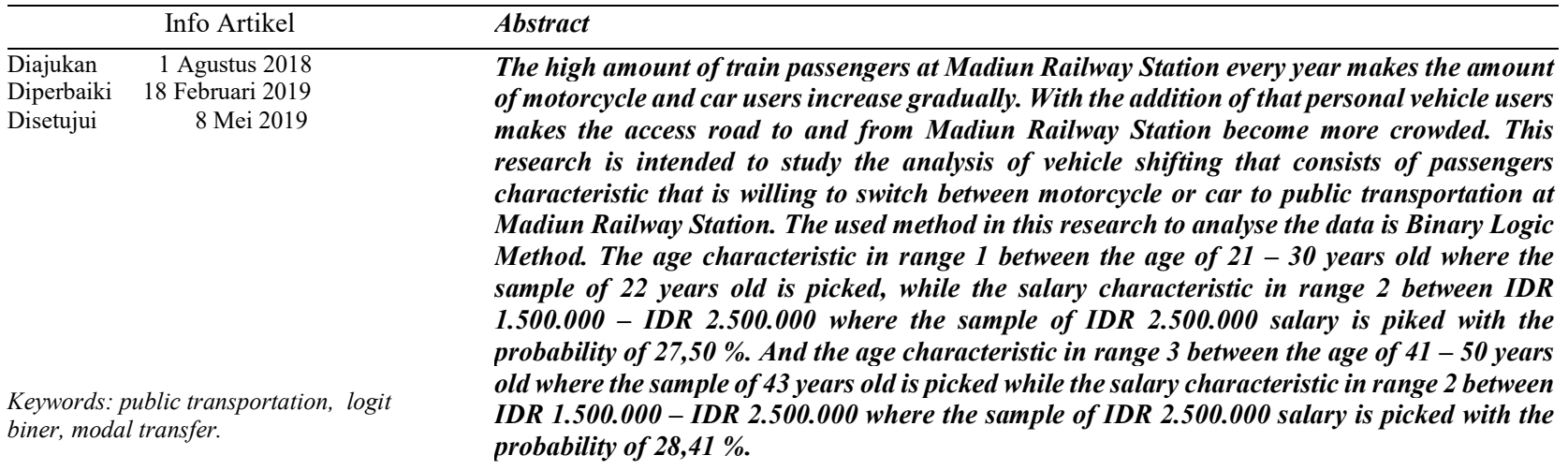

Abstrak

Tingginya jumlah penumpang di stasiun Madiun yang terjadi setiap tahunnya, membuat peningkatan jumlah pengguna sepeda motor dan mobil pribadi. Dengan bertambahnya jumlah pengguna kendaraan pribadi tersebut, membuat ruas jalan akses ke dan dari stasiun Madiun menjadi padat. Studi ini bertujuan untuk mengenai analisa perpindahan untuk mengetahui karakteristik penumpang yang bersedia untuk berpindah moda dari sepeda motor dan mobil pribadi ke angkutan umum di stasiun Madiun. Metode yang digunakan untuk menganalisa data menggunakan metode logit biner. Karakteristik usia dalam range 1 yaitu 21-30 tahun dimana diambil sampel 22 tahun dan penghasilan dalam range 2 yaitu $R p$ 1.500.000-Rp 2.500 .000 dimana diambil sampel di penghasilan $R p$ 2.500 .000 probabilitasnya sebesar $27,50 \%$. Karakteristik usia dalam range 3 yaitu $41-50$ tahun dimana diambil sampel 43 tahun dan penghasilan dalam range 2 yaitu $R p 1.500 .000$ -

Kata kunci: angkutan umum, logit biner, perpindahan moda Rp 2.500.000 dimana diambil sampel di penghasilan $R p$ 2.500.000 probabilitasnya sebesar $28,41 \%$.

\section{Pendahuluan}

Pesatnya pertumbuhan penumpang kereta api di stasiun Madiun terjadi pada setiap tahunnya. Pada tahun 2017 jumlah penumpang yang naik dan turun dari stasiun Madiun mencapai 1,5 juta penumpang (PT. Kereta Api Indonesia Daop 7 Madiun). Penumpang kereta api di stasiun Madiun jarang yang menggunakan angkutan umum. Menurut para penumpang bila naik angkutan umum waktu tempuhnya jauh lebih lama karena angkutan umum banyak yang sering ngetem sehingga penumpang takut ketinggalan kereta. Sepeda motor dan mobil pribadi merupakan kendaraan yang dominan digunakan penumpang, baik dari maupun ke stasiun Madiun.

Dengan pertumbuhan penumpang kereta api yang terjadi pada setiap tahunnya maka akan berdampak pula pada peningkatan jumlah penumpang yang menggunakan sepeda motor dan mobil pribadi di stasiun Madiun. Kedepan kemungkinan besar akan terjadi kepadatan volume lalu lintas, terutama pada saat peak hour baik dari maupun ke stasiun Madiun yang dapat menyebabkan waktu tempuh dan biaya operasional semakin bertambah. Kunci dari kemudahan perpindahan moda dari sepeda motor dan mobil pribadi ke angkutan umum diperlukan suatu integrasi yang menarik[1]. Jika perpindahan diantara moda transportasi tersebut dibuat menjadi lebih mudah, lebih cepat dan lebih nyaman, maka perpindahan moda dan fleksibilitas dari keseluruhan jaringan akan meningkat dengan pesat[2]. Beberapa karakteristik yang mempengaruhi pemilihan moda antara lain jaminan keselamatan dan keamanan, kecepatan, keterjangkauan tarif, asal dan tujuan perjalanan, maksud perjalanan[3],[4]. Dengan mengetahui variabel karakteristik apa saja yang 
mempengaruhi probabilitas pemilihan moda maka akan dapat dilakukan upaya perbaikan dan peningkatan pelayanan[5]. Diharapkan dengan kondisi pelayanan angkutan umum yang semakin meningkat nantinya penumpang akan lebih memilih menggunakan angkutan umum dalam melakukan perjalanannya sehingga akan mengurangi beban jalan. Dengan latar belakang permasalahan tersebut maka perlu adanya analisis untuk mengetahui karakteristik penumpang yang bersedia untuk berpindah moda dari sepeda motor dan mobil pribadi ke angkutan umum di stasiun Madiun. Karakteristik apa saja yang menjadi pertimbangan penumpang untuk berpindah moda dari sepeda motor dan mobil pribadi ke angkutan umum di stasiun Madiun.

\section{Metode}

Penelitian ini termasuk dalam analisis data deskriptif kuantitatif. Metode yang digunakan meliputi indentifikasi masalah yang bertujuan untuk mempermudah pembahasan, studi kondisi awal lapangan bertujuan untuk mengetahui kondisi awal lapangan sehingga dapat mempersiapkan keperluan saat pengambilan data primer[6]. Dalam penelitan ini sampel dipilih secara acak atau random sampel dimana sampel merupakan penumpang di stasiun Madiun. Teknik pengumpulan data dilakukan dengan interview atau wawancara terstruktur dengan menggunakan kuesioner. Terlebih dahulu dilakukan survey pendahuluan atau survey lapangan untuk mempersiapkan keperluan saat pengambilan data.

Data yang diperoleh dianalisis menggunakan regresi logit biner untuk mengetahui karakteristik apa saja yang menjadi pertimbangan penumpang untuk berpindah moda dari sepeda motor dan mobil pribadi ke angkutan umum di stasiun Madiun.

\section{Hasil dan Pembahasan}

Setelah diperoleh data dari hasil survey maka dilakukan analisa deskripsi karakteristik responden dan analisis perpindahan modanya.

\section{1). Karakteristik Responden}

Karakteristik pengguna kendaraan pribadi dalam penelitian ini dari segi jenis kelamin sampel, responden perempuan mungkin akan relatif lebih mementingkan keamanan dan kenyamanan dalam bertransportasi, sehingga pemilihan moda transportasi juga akan berbeda. Dari segi usia responden mungkin akan mempengaruhi perilakunya dalam aktivitas, mereka yang muda relatif tidak khawatir menggunakan sepeda motor atau naik angkutan kota, dibandingkan mereka yang berusia lanjut. Tingkat pendapatan juga akan sangat mempengaruhi seseorang dalam melakukan pemilihan moda. Mereka yang berpenghasilan tinggi mungkin akan lebih memilih menggunakan kendaraan pribadi mobil pribadi dari pada menggunakan angkutan umum.

Tabel 1. Karakteristik Responden

\begin{tabular}{|c|c|c|}
\hline Karakteristik & Keterangan & Persentase \\
\hline Jenis & Perempuan & $59 \%$ \\
\hline Kelamin & Laki-laki & $41 \%$ \\
\hline \multirow[t]{5}{*}{ Usia } & $<20$ tahun & $21 \%$ \\
\hline & 21-30 tahun & $35 \%$ \\
\hline & $31-40$ tahun & $19 \%$ \\
\hline & 41-50 tahun & $11 \%$ \\
\hline & $>50$ tahun & $14 \%$ \\
\hline Pendidikan & SD/SMP & $10 \%$ \\
\hline \multirow[t]{4}{*}{ Terakhir } & SMA & $42 \%$ \\
\hline & $\mathrm{D} 1 / \mathrm{D} 2 / \mathrm{D} 3$ & $13 \%$ \\
\hline & $\mathrm{D} 4 / \mathrm{S} 1$ & $32 \%$ \\
\hline & $\mathrm{S} 2 / \mathrm{S} 3$ & $3 \%$ \\
\hline \multirow[t]{6}{*}{ Pekerjaan } & Pelajar/mahasiswa & $34 \%$ \\
\hline & PNS/TNI/POLRI & $7 \%$ \\
\hline & BUMN & $7 \%$ \\
\hline & Pegawai swasta & $34 \%$ \\
\hline & Wiraswata/pengusaha & $14 \%$ \\
\hline & Lainnya & $4 \%$ \\
\hline \multirow[t]{5}{*}{ Penghasilan } & Belum berpenghasilan & $23 \%$ \\
\hline & Rp500.000-Rp1.500.000 & $24 \%$ \\
\hline & Rp1.500.000-Rp2.500.000 & $21 \%$ \\
\hline & Rp2.500.000-Rp5.000.000 & $23 \%$ \\
\hline & $\mathrm{Rp}>5.000 .000$ & $9 \%$ \\
\hline Asal & Madiun & $34 \%$ \\
\hline \multirow[t]{5}{*}{ Perjalanan } & Magetan & $40 \%$ \\
\hline & Ponorogo & $19 \%$ \\
\hline & Ngawi & $2 \%$ \\
\hline & Trenggalek & $1 \%$ \\
\hline & Pacitan & $4 \%$ \\
\hline \multirow{6}{*}{$\begin{array}{l}\text { Maksud } \\
\text { perjalanan }\end{array}$} & Perjalanan dinas & $12 \%$ \\
\hline & Urusan bisnis & $7 \%$ \\
\hline & Rekreasi/liburan & $6 \%$ \\
\hline & Mengunjungi keluarga & $53 \%$ \\
\hline & Kuliah/sekolah & $17 \%$ \\
\hline & Lainnya & $5 \%$ \\
\hline \multirow{5}{*}{$\begin{array}{l}\text { Frekuensi } \\
\text { perjalanan }\end{array}$} & Seminggu sekali & $6 \%$ \\
\hline & Sebulan sekali & $13 \%$ \\
\hline & Sebulan 2kali & $9 \%$ \\
\hline & Setahun sekali & $35 \%$ \\
\hline & Lainnya & $37 \%$ \\
\hline
\end{tabular}

Sumber: Hasil pengolahan data primer

2). Analisis Perpindahan Moda Dari Sepeda Motor dan Mobil Pribadi ke Angkutan Umum Berdasarkan Jumlah Sampel

Hasil survey didapat sebanyak 150 responden untuk penumpang sepeda motor dan mobil pribadi. Dari jumlah sampel kemauan berpindah responden untuk beralih moda 
dari kendaraan pribadi sepeda motor dan mobil pribadi ke angkutan umum yaitu sebesar 84 responden atau 56\% mau beralih moda menggunakan angkutan umum dan sisanya sebesar 66 responden atau 44\% tetap memilih menggunakan kendaraan pribadi.

\section{3). Analisis Perpindahan Moda Dari Sepeda Motor dan Mobil} Pribadi ke Angkutan Umum Berdasarkan Karakteristik.

Analisa perpindahan moda berdasarkan karakteristik dilakukan pengujian secara multivariate dimana semua variabel dimasukan secara bersamaan dengan tujuan untuk mengetahui ada atau tidaknya hubungan antara variabel tersebut yang meliputi jenis kelamin, usia, pekerjaan, penghasilan, asal tujuan dan maksud perjalanan.

Tabel 2. Hasil Uji Chi-square

\begin{tabular}{lcll}
\hline Variabel bebas & df & $\begin{array}{l}\text { Chi- } \\
\text { square }\end{array}$ & Sig. \\
\hline Jenis Kelamin & 1 & 2,486 & 0,115 \\
Usia & 4 & 10,431 & 0,034 \\
Pendidikan & 4 & 3,893 & 0,421 \\
Terakhir & 5 & 6,608 & 0,252 \\
Pekerjaan & 4 & 9,153 & 0,057 \\
Penghasilan & 5 & 6,188 & 0,288 \\
Asal perjalanan & 4 & 6,814 & 0,146 \\
Frekwensi & 5 & 9,696 & 0,084 \\
perjalanan & Maksud perjalanan & 5 &
\end{tabular}

Sumber: Hasil pengolahan data primer

Berdasarkan hasil uji chi-square diatas dapat disimpulkan terdapat atau ada variabel yang memiliki hubungan dengan perilaku penumpang kereta api dalam memilih moda yang akan digunakan antara lain variabel usia, penghasilan, dan maksud perjalanan. Atau dapat disimpulkan variabel usia, penghasilan, dan maksud perjalanan tersebut mempengaruhi model secara multivariate.

Uji secara parsial dapat disebut juga dengan uji Wald yang digunakan untuk menguji model logistik secara parsial atau menguji variabel independen terhadap variabel dependen. Untuk menguji signifikan variabel pada uji Wald adalah jika nilai sig $<0,1$. Untuk hasil uji Wald dapat dilihat pada Tabel 3.

Kriteria uji: tolak Ho jika nilai Wald $>$ nilai $\mathrm{X}^{2} 0,1$ atau nilai $\operatorname{sig}<\alpha$

Taraf signifikansi $\alpha=10 \%$

Pengujian signifikansi dari variabel bebas yang tertera pada Tabel 3 tersebut untuk mendapatkan peubah mana yang berpengaruh secara signifikan terhadap variabel terikat dan diperlukan dalam model adalah sebagai berikut: a. Usia responden dengan nilai Wald sebesar 8,128 lebih besar dari nilai $\mathrm{X}^{2} 0,1$ sebesar 2,706 atau nilai $\mathrm{p}$-value/sig sebesar 0,004 kurang dari 0,1 yang berarti bahwa hipotesis awal tidak ada pengaruh antara ada atau tidaknya usia responden terhadap pemilihan moda antara kendaraan pribadi atau angkutan umum ditolak. Sehingga dapat disimpulkan bahwa variabel bebas usia responden berpengaruh secara signifikan terhadap perilaku pemilihan moda.

b. Penghasilan responden dengan nilai Wald sebesar 3,569 lebih besar dari nilai $\mathrm{X}^{2} 0,1$ sebesar 2,706 atau nilai $\mathrm{p}$ value/sig sebesar 0,059 kurang dari 0,1 yang berarti bahwa hipotesis awal tidak ada pengaruh antara ada atau tidaknya harga tiket terhadap pemilihan moda antara kendaraan pribadi atau angkutan umum ditolak. Sehingga dapat disimpulkan bahwa variabel bebas penghasilan responden berpengaruh secara signifikan terhadap perilaku pemilihan moda.

c. Maksud perjalanan dengan nilai Wald sebesar 1,756 lebih kecil dari nilai $\mathrm{X}^{2}$ 0,1 sebesar 2,706 atau nilai p-value/sig sebesar 0,185 lebih dari 0,1 yang berarti bahwa hipotesis awal tidak ada pengaruh antara ada atau tidaknya harga tiket terhadap pemilihan moda antara kendaraan pribadi atau angkutan umum diterima. Sehingga dapat disimpulkan bahwa variabel bebas maksud perjalanan tidak berpengaruh secara signifikan terhadap perilaku pemilihan moda.

Dapat disimpulkan bahwa terdapat 2 variabel bebas yang berpengaruh signifikan yaitu usia responden dan penghasilan responden. Oleh sebab itu untuk variabel maksud perjalanan dieliminasi dan tidak diikutsertakan pada analisis selanjutnya karena tidak berpengaruh secara signifikan terhadap perilaku pemilihan moda.

Setelah dilakukan uji signifikansi terhadap model maka diperoleh hasil bahwa variabel yang berpengaruh signifikan terhadap perilaku pemilihan moda yaitu variabel usia dan variabel penghasilan. Selanjutnya dari kedua variabel yang berpengaruh signifikan tersebut dilakukan analisis kembali dengan pengkategorian tiap variabel.

Tabel 3. Hasil Uji Wald

\begin{tabular}{lrrrrr}
\hline & B & S.E. & & Sig. & $\operatorname{Exp(B)}$ \\
\hline Usia & .443 & .155 & 8.128 & .004 & 1.557 \\
Penghasilan & -.301 & .159 & 3.569 & .059 & .740 \\
Maksud & -.192 & .145 & 1.756 & .185 & .826 \\
Constant & .079 & .782 & .010 & .919 & 1.082 \\
\hline
\end{tabular}

Sumber: Hasil pengolahan data primer 
Tabel 4. Hasil Uji Wald

\begin{tabular}{lrrrrr}
\hline & \multicolumn{1}{c}{ B } & S.E. & & Sig. & $\operatorname{Exp}(\mathrm{B})$ \\
\hline Usia & -1.610 & .727 & 10.258 & 0.36 & \\
Usia(1) & -926 & .575 & 4.910 & 0.27 & .200 \\
Usia(2) & -1.204 & .641 & 2.593 & .107 & .396 \\
Usia(3) & .449 & .758 & 3.532 & .060 & .300 \\
Usia(4) & & & .351 & .554 & 1.567 \\
Penghasilan & 1.750 & .839 & 8943 & .063 & \\
Penghasilan(1) & 1.920 & .835 & 4.356 & .037 & 5.757 \\
Penghasilan(2) & .852 & .812 & 5.280 & .022 & 6.819 \\
Penghasilan(3) & 1.877 & .784 & 1.099 & .295 & 2.343 \\
Penghasilan(4) & -.897 & .791 & 5.729 & .017 & 6.532 \\
Constant & & & 1.287 & .257 & .408 \\
\hline Sumber: Hasilpengolahan
\end{tabular}

Sumber: Hasil pengolahan data primer

Berdasarkan Tabel 4. dapat dilihat bahwa usia (1), usia (3), penghasilan (1), penghasilan (2), dan penghasilan (4) berpengaruh signifikan terhadap variabel respon/tidak bebas. Untuk usia (1) range usia 21-30 tahun, usia (3) range usia 4150 tahun, penghasilan (1) range Rp 500.000-Rp 1.500.000, penghasilan (2) range $\mathrm{Rp} 1.000 .000-\mathrm{Rp} 2.500 .000$, penghasilan (4) range $>$ Rp 5.000.000.

Dari hasil tersebut didapatkan beberapa persamaan logit pemilihan moda kendaraan pribadi dengan angkutan umum. Dan di ambil contoh sampel yaitu sebagai berikut:

a. Persamaan logit pemilihan moda kendaraan pribadi dengan angkutan umum untuk karakteristik usia (1) range usia 21-30 tahun dan penghasilan (1) Rp 500.000-Rp 1.500.000 didapatkan persamaan

$$
\begin{aligned}
\operatorname{Logit}(p) & =\ln \frac{p}{1-p} \\
= & \beta_{0} \pm \sum_{k-1}^{p} \beta_{\mathrm{k}} \mathrm{X}_{\mathrm{k}} \\
= & -0,897-1,610 \text { Usia1 }+1,750 \text { Penghasilan1 }
\end{aligned}
$$

Hasil dari persamaan logit tersebut kemudian dimasukkan ke dalam rumus perhitungan probabilitas

$P=\frac{\exp ^{\log i t(p)}}{1+\exp ^{\log i t(p)}}$

b. Persamaan logit pemilihan moda kendaraan pribadi dengan angkutan umum untuk karakteristik usia (1) range usia 21-30 tahun dan penghasilan (2) dengan range penghasilan Rp 1.500.000-Rp 2.500.000 didapatkan persamaan

$$
\begin{aligned}
\operatorname{Logit} & (p)=\ln \frac{p}{1-p} \\
= & \beta_{0} \pm \sum_{k-1}^{p} \beta_{\mathrm{k}} \mathrm{X}_{\mathrm{k}} \\
= & -0,897-1,610 \text { Usia1 }+1,920 \text { Penghasilan2 }
\end{aligned}
$$

Hasil dari persamaan logit tersebut kemudian dimasukan ke dalam rumus perhitungan probabilitas

$P=\frac{\exp ^{\operatorname{logit}(p)}}{1+\exp ^{\log i t(p)}}$ c. Persamaan logit pemilihan moda kendaraan pribadi dengan angkutan umum untuk karakteristik usia (1) range usia 21-30 tahun dan penghasilan (4) dengan range penghasilan $>\operatorname{Rp} 5.000 .000$ didapatkan persamaan

$$
\begin{aligned}
\operatorname{Logit} & (p)=\ln \frac{p}{1-p} \\
= & \beta_{0} \pm \sum_{k-1}^{p} \beta_{\mathrm{k}} \mathrm{X}_{\mathrm{k}} \\
= & -0,897-1,610_{\text {Usia } 1}+1,877 \text { Penghasilan4 }
\end{aligned}
$$

Hasil dari persamaan logit tersebut kemudian dimasukkan ke dalam rumus perhitungan probabilitas

$P=\frac{\exp ^{\log i t(p)}}{1+\exp ^{\log i t(p)}}$

d. Persamaan logit pemilihan moda kendaraan pribadi dengan angkutan umum untuk karakteristik usia (3) range usia 41-50 tahun dan penghasilan (1) Rp 500.000-Rp 1.500.000 didapatkan persamaan

\begin{tabular}{|c|c|c|c|}
\hline Usia 1 & Penghasilan 1 & Logit (p) & $\mathrm{P}(\%)$ \\
\hline 22 tahun & Rp 750.000 & -0.968 & $27.53 \%$ \\
\hline 24 tahun & Rp 750.000 & -0.962 & $27.65 \%$ \\
\hline 26 tahun & Rp 750.000 & -0.957 & $27.76 \%$ \\
\hline 28 tahun & $\mathrm{Rp} 750.000$ & -0.952 & $27.85 \%$ \\
\hline 30 tahun & Rp 750.000 & -0.948 & $27.92 \%$ \\
\hline Usia 1 & Penghasilan 1 & Logit (p) & $\mathrm{P}(\%)$ \\
\hline 22 tahun & Rp 1.250 .000 & -0.969 & $27.51 \%$ \\
\hline 24 tahun & Rp 1.250 .000 & -0.963 & $27.64 \%$ \\
\hline 26 tahun & Rp 1.250 .000 & -0.958 & $27.74 \%$ \\
\hline 28 tahun & $\mathrm{Rp} 1.250 .000$ & -0.953 & $27.83 \%$ \\
\hline 30 tahun & Rp 1.250 .000 & -0.949 & $27.91 \%$ \\
\hline Usia 1 & Penghasilan 1 & Logit (p) & $\mathrm{P}(\%)$ \\
\hline 22 tahun & Rp 1.500 .000 & -0.969 & $27.51 \%$ \\
\hline 24 tahun & Rp 1.500 .000 & -0.963 & $27.63 \%$ \\
\hline 26 tahun & Rp 1.500.000 & -0.958 & $27.73 \%$ \\
\hline 28 tahun & Rp 1.500 .000 & -0.953 & $27.82 \%$ \\
\hline 30 tahun & $\mathrm{Rp} 1.500 .000$ & -0.950 & $27.90 \%$ \\
\hline
\end{tabular}

$$
\begin{aligned}
\operatorname{Logit} & (p)=\ln \frac{p}{1-p} \\
= & \beta_{0} \pm \sum_{k-1}^{p} \beta_{\mathrm{k}} \mathrm{X}_{\mathrm{k}} \\
= & -0,897-1,204 \text { Usia3 }+1,750 \text { Penghasilan1 }
\end{aligned}
$$

Hasil dari persamaan logit tersebut kemudian dimasukan ke dalam rumus perhitungan probabilitas

$P=\frac{\exp ^{\log i t(p)}}{1+\exp ^{\log i t(p)}}$

Tabel 5. Nilai Probabilitas Untuk Usia (1) dan Penghasilan (1)

Sumber: Hasil pengolahan data

e. Persamaan logit pemilihan moda kendaraan pribadi dengan angkutan umum untuk karakteristik usia (3) range 
usia 31-40 tahun dan penghasilan (2) Rp 1.500.000-Rp 2.500.000 didapatkan persamaan

$$
\begin{aligned}
\operatorname{Logit} & (p)=\ln \frac{p}{1-p} \\
= & \beta_{0} \pm \sum_{k-1}^{p} \beta_{\mathrm{k}} \mathrm{X}_{\mathrm{k}} \\
= & -0,897-1,204 \text { Usia3 }+1,920 \text { Penghasilan2 }
\end{aligned}
$$

Hasil dari persamaan logit tersebut kemudian dimasukkan ke dalam rumus perhitungan probabilitas

$P=\frac{\exp ^{\operatorname{logit}(p)}}{1+\exp ^{\operatorname{logit}(p)}}$

\begin{tabular}{|c|c|c|c|}
\hline Usia 1 & Penghasilan 2 & Logit (p) & $\mathrm{P}(\%)$ \\
\hline 22 tahun & Rp 1.750 .000 & -0.969 & $27.51 \%$ \\
\hline 24 tahun & $\mathrm{Rp} 1.750 .000$ & -0.963 & $27.63 \%$ \\
\hline 26 tahun & $\mathrm{Rp} 1.750 .000$ & -0.958 & $27.73 \%$ \\
\hline 28 tahun & Rp 1.750 .000 & -0.953 & $27.82 \%$ \\
\hline 30 tahun & Rp 1.750 .000 & -0.950 & $27.90 \%$ \\
\hline Usia 1 & Penghasilan 2 & Logit (p) & $\mathrm{P}(\%)$ \\
\hline 22 tahun & Rp 2.250 .000 & -0.969 & $27.50 \%$ \\
\hline 24 tahun & Rp 2.250 .000 & -0.963 & $27.63 \%$ \\
\hline 26 tahun & $\operatorname{Rp} 2.250 .000$ & -0.958 & $27.73 \%$ \\
\hline 28 tahun & Rp 2.250 .000 & -0.954 & $27.82 \%$ \\
\hline 30 tahun & Rp 2.250.000 & -0.950 & $27.89 \%$ \\
\hline Usia 1 & Penghasilan 2 & Logit (p) & $\mathrm{P}(\%)$ \\
\hline 22 tahun & Rp 2.500.000 & -0.969 & $27.50 \%$ \\
\hline 24 tahun & Rp 2.500 .000 & -0.963 & $27.62 \%$ \\
\hline 26 tahun & Rp 2.500 .000 & -0.958 & $27.73 \%$ \\
\hline 28 tahun & Rp 2.500 .000 & -0.954 & $27.82 \%$ \\
\hline 30 tahun & Rp 2.500 .000 & -0.950 & $27.89 \%$ \\
\hline
\end{tabular}

Tabel 6. Nilai Probabilitas Untuk Usia (1) dan Penghasilan (2)

Sumber: Hasil pengolahan data

Tabel 7. Nilai Probabilitas Untuk Usia (1) dan Penghasilan (4)

\begin{tabular}{rccc}
\hline Usia 1 & Penghasilan 4 & Logit (p) & P $(\%)$ \\
22 tahun & Rp 5.000.000 & -0.970 & $27.49 \%$ \\
24 tahun & Rp 5.000.000 & -0.964 & $27.62 \%$ \\
26 tahun & Rp 5.000.000 & -0.959 & $27.72 \%$ \\
28 tahun & Rp 5.000.000 & -0.954 & $27.81 \%$ \\
30 tahun & Rp 5.000.000 & -0.950 & $27.88 \%$ \\
\hline Usia 1 & Penghasilan 4 & Logit $(\mathrm{p})$ & P $(\%)$ \\
22 tahun & Rp 5.000.000 & -0.970 & $27.49 \%$ \\
24 tahun & Rp 5.000.000 & -0.964 & $27.62 \%$ \\
26 tahun & Rp 5.000.000 & -0.959 & $27.72 \%$ \\
28 tahun & Rp 5.000.000 & -0.954 & $27.81 \%$ \\
30 tahun & Rp 5.000.000 & -0.950 & $27.88 \%$ \\
\hline Usia 1 & Penghasilan 4 & Logit (p) & P $(\%)$ \\
22 tahun & Rp 10.000 .000 & -0.970 & $27.49 \%$ \\
24 tahun & Rp 10.000 .000 & -0.964 & $27.61 \%$ \\
26 tahun & Rp 10.000 .000 & -0.959 & $27.72 \%$ \\
28 tahun & Rp 10.000 .000 & -0.954 & $27.80 \%$ \\
30 tahun & Rp 10.000 .000 & -0.950 & $27.88 \%$ \\
\hline
\end{tabular}

Sumber: Hasil pengolahan data f. Persamaan logit pemilihan moda kendaraan pribadi dengan angkutan umum untuk karakteristik usia (3) range usia 31-40 tahun dan penghasilan (4) >Rp 5.000.000 didapatkan persamaan

$$
\begin{aligned}
\operatorname{Logit} & (p)=\ln \frac{p}{1-p} \\
& =\beta_{0} \pm \sum_{k-1}^{p} \beta_{\mathrm{k}} \mathrm{X}_{\mathrm{k}} \\
& =-0,897-1,204 \text { Usia3 }+1,877 \text { Penghasilan4 }
\end{aligned}
$$

Hasil dari persamaan logit tersebut kemudian

\begin{tabular}{|c|c|c|c|}
\hline Usia 3 & Penghasilan 1 & Logit (p) & $\mathrm{P}(\%)$ \\
\hline 41 tahun & Rp 750.000 & -0.924 & $28.42 \%$ \\
\hline 42 tahun & Rp 750.000 & -0.923 & $28.43 \%$ \\
\hline 43 tahun & Rp 750.000 & -0.923 & $28.44 \%$ \\
\hline 44 tahun & $\operatorname{Rp} 750.000$ & -0.922 & $28.46 \%$ \\
\hline 45 tahun & Rp 750.000 & -0.921 & $28.47 \%$ \\
\hline 46 tahun & $\operatorname{Rp} 750.000$ & -0.921 & $28.48 \%$ \\
\hline 47 tahun & $\operatorname{Rp} 750.000$ & -0.920 & $28.49 \%$ \\
\hline 48 tahun & Rp 750.000 & -0.920 & $28.50 \%$ \\
\hline 49 tahun & $\operatorname{Rp} 750.000$ & -0.919 & $28.51 \%$ \\
\hline 50 tahun & Rp 750.000 & -0.919 & $28.52 \%$ \\
\hline Usia 3 & Penghasilan 1 & Logit (p) & $\mathrm{P}(\%)$ \\
\hline 41 tahun & Rp 1.250 .000 & -0.925 & $28.40 \%$ \\
\hline 42 tahun & $\operatorname{Rp} 1.250 .000$ & -0.924 & $28.41 \%$ \\
\hline 43 tahun & $\operatorname{Rp} 1.250 .000$ & -0.924 & $28.42 \%$ \\
\hline 44 tahun & $\operatorname{Rp} 1.250 .000$ & -0.923 & $28.44 \%$ \\
\hline 45 tahun & $\operatorname{Rp} 1.250 .000$ & -0.922 & $28.45 \%$ \\
\hline 46 tahun & Rp 1.250 .000 & -0.922 & $28.46 \%$ \\
\hline 47 tahun & Rp 1.250 .000 & -0.921 & $28.47 \%$ \\
\hline 48 tahun & $\operatorname{Rp} 1.250 .000$ & -0.921 & $28.48 \%$ \\
\hline 49 tahun & $\operatorname{Rp} 1.250 .000$ & -0.920 & $28.49 \%$ \\
\hline 50 tahun & Rp 1.250 .000 & -0.920 & $28.50 \%$ \\
\hline Usia 3 & Penghasilan 1 & $\operatorname{Logit}(\mathrm{p})$ & $\mathrm{P}(\%)$ \\
\hline 41 tahun & Rp 1.500 .000 & -0.925 & $28.39 \%$ \\
\hline 42 tahun & Rp 1.500 .000 & -0.925 & $28.41 \%$ \\
\hline 43 tahun & Rp 1.500.000 & -0.924 & $28.42 \%$ \\
\hline 44 tahun & Rp 1.500 .000 & -0.923 & $28.43 \%$ \\
\hline 45 tahun & Rp 1.500 .000 & -0.923 & $28.45 \%$ \\
\hline 46 tahun & $\operatorname{Rp} 1.500 .000$ & -0.922 & $28.46 \%$ \\
\hline 47 tahun & Rp 1.500 .000 & -0.921 & $28.47 \%$ \\
\hline 48 tahun & Rp 1.500 .000 & -0.921 & $28.48 \%$ \\
\hline 49 tahun & Rp 1.500.000 & -0.920 & $28.49 \%$ \\
\hline 50 tahun & $\operatorname{Rp} 1.500 .000$ & -0.920 & $28.50 \%$ \\
\hline
\end{tabular}
dimasukkan ke dalam rumus perhitungan probabilitas

$P=\frac{\exp ^{\log i t(p)}}{1+\exp ^{\log i t(p)}}$

Tabel 8. Nilai Probabilitas Untuk Usia (3) dan Penghasilan (1)

Sumber: Hasil pengolahan data 
Tabel 9. Nilai Probabilitas Untuk Usia (3) Dan Penghasilan (2)

\begin{tabular}{|c|c|c|c|}
\hline Usia 3 & Penghasilan 2 & Logit (p) & $\mathrm{P}(\%)$ \\
\hline 41 tahun & Rp 1.750 .000 & -0.925 & $28.39 \%$ \\
\hline 42 tahun & Rp 1.750 .000 & -0.925 & $28.40 \%$ \\
\hline 43 tahun & Rp 1.750 .000 & -0.924 & $28.42 \%$ \\
\hline 44 tahun & Rp 1.750 .000 & -0.923 & $28.43 \%$ \\
\hline 45 tahun & $\operatorname{Rp} 1.750 .000$ & -0.923 & $28.44 \%$ \\
\hline 46 tahun & $\mathrm{Rp} 1.750 .000$ & -0.922 & $28.46 \%$ \\
\hline 47 tahun & Rp 1.750 .000 & -0.922 & $28.47 \%$ \\
\hline 48 tahun & Rp 1.750 .000 & -0.921 & $28.48 \%$ \\
\hline 49 tahun & Rp 1.750 .000 & -0.920 & $28.49 \%$ \\
\hline 50 tahun & Rp 1.750 .000 & -0.920 & $28.50 \%$ \\
\hline Usia 3 & Penghasilan 2 & Logit (p) & $\mathrm{P}(\%)$ \\
\hline 41 tahun & Rp 2.250.000 & -0.926 & $28.39 \%$ \\
\hline 42 tahun & Rp 2.250 .000 & -0.925 & $28.40 \%$ \\
\hline 43 tahun & $\operatorname{Rp} 2.250 .000$ & -0.924 & $28.41 \%$ \\
\hline 44 tahun & Rp 2.250 .000 & -0.924 & $28.43 \%$ \\
\hline 45 tahun & Rp 2.250 .000 & -0.923 & $28.44 \%$ \\
\hline 46 tahun & Rp 2.250 .000 & -0.922 & $28.45 \%$ \\
\hline 47 tahun & Rp 2.250 .000 & -0.922 & $28.46 \%$ \\
\hline 48 tahun & Rp 2.250 .000 & -0.921 & $28.47 \%$ \\
\hline 49 tahun & Rp 2.250 .000 & -0.921 & $28.48 \%$ \\
\hline 50 tahun & $\operatorname{Rp} 2.250 .000$ & -0.920 & $28.49 \%$ \\
\hline Usia 3 & Penghasilan 2 & Logit (p) & $\mathrm{P}(\%)$ \\
\hline 41 tahun & Rp 2.500.000 & -0.926 & $28.38 \%$ \\
\hline 42 tahun & Rp 2.500 .000 & -0.925 & $28.40 \%$ \\
\hline 43 tahun & Rp 2.500 .000 & -0.924 & $28.41 \%$ \\
\hline 44 tahun & Rp 2.500 .000 & -0.924 & $28.42 \%$ \\
\hline 45 tahun & $\operatorname{Rp} 2.500 .000$ & -0.923 & $28.44 \%$ \\
\hline 46 tahun & Rp 2.500 .000 & -0.922 & $28.45 \%$ \\
\hline 47 tahun & $\operatorname{Rp} 2.500 .000$ & -0.922 & $28.46 \%$ \\
\hline 48 tahun & $\operatorname{Rp} 2.500 .000$ & -0.921 & $28.47 \%$ \\
\hline 49 tahun & Rp 2.500 .000 & -0.921 & $28.48 \%$ \\
\hline 50 tahun & Rp 2.500 .000 & -0.920 & $28.49 \%$ \\
\hline
\end{tabular}

Sumber: Hasil pengolahan data

Tabel 10. Nilai Probabilitas Untuk Usia (3) dan Penghasilan (4)

\begin{tabular}{cccc}
\hline Usia 3 & Penghasilan 4 & Logit $(\mathrm{p})$ & $\mathrm{P}(\%)$ \\
41 tahun & $\mathrm{Rp} 5.000 .000$ & -0.926 & $28.38 \%$ \\
42 tahun & $\operatorname{Rp} 5.000 .000$ & -0.925 & $28.39 \%$ \\
43 tahun & $\operatorname{Rp} 5.000 .000$ & -0.925 & $28.40 \%$ \\
44 tahun & $\operatorname{Rp} 5.000 .000$ & -0.924 & $28.42 \%$ \\
45 tahun & $\operatorname{Rp} 5.000 .000$ & -0.923 & $28.43 \%$ \\
46 tahun & $\operatorname{Rp} 5.000 .000$ & -0.923 & $28.44 \%$ \\
47 tahun & $\operatorname{Rp} 5.000 .000$ & -0.922 & $28.45 \%$ \\
48 tahun & $\operatorname{Rp} 5.000 .000$ & -0.922 & $28.46 \%$ \\
49 tahun & $\operatorname{Rp} 5.000 .000$ & -0.921 & $28.47 \%$ \\
50 tahun & $\operatorname{Rp} 5.000 .000$ & -0.921 & $28.48 \%$ \\
\hline
\end{tabular}

Tabel 10. Nilai Probabilitas Untuk Usia (3) dan Penghasilan (4) lanjutan

\begin{tabular}{cccc}
\hline Usia 3 & Penghasilan 4 & Logit (p) & P (\%) \\
41 tahun & Rp 7.000.000 & -0.926 & $28.37 \%$ \\
42 tahun & Rp 7.000.000 & -0.925 & $28.39 \%$ \\
43 tahun & Rp 7.000.000 & -0.925 & $28.40 \%$ \\
44 tahun & Rp 7.000.000 & -0.924 & $28.41 \%$ \\
45 tahun & Rp 7.000.000 & -0.923 & $28.43 \%$ \\
46 tahun & Rp 7.000.000 & -0.923 & $28.44 \%$ \\
47 tahun & Rp 7.000.000 & -0.922 & $28.45 \%$ \\
48 tahun & Rp 7.000.000 & -0.922 & $28.46 \%$ \\
49 tahun & Rp 7.000.000 & -0.921 & $28.47 \%$ \\
50 tahun & Rp 7.000.000 & -0.921 & $28.48 \%$ \\
\hline Usia 3 & Penghasilan 4 & Logit (p) & P $(\%)$ \\
41 tahun & Rp 10.000.000 & -0.926 & $28.37 \%$ \\
42 tahun & Rp 10.000.000 & -0.925 & $28.39 \%$ \\
43 tahun & Rp 10.000.000 & -0.925 & $28.40 \%$ \\
44 tahun & Rp 10.000.000 & -0.924 & $28.41 \%$ \\
45 tahun & Rp 10.000.000 & -0.924 & $28.43 \%$ \\
46 tahun & Rp 10.000.000 & -0.923 & $28.44 \%$ \\
47 tahun & Rp 10.000.000 & -0.922 & $28.45 \%$ \\
48 tahun & Rp 10.000.000 & -0.922 & $28.46 \%$ \\
49 tahun & Rp 10.000.000 & -0.921 & $28.47 \%$ \\
50 tahun & Rp 10.000.000 & -0.921 & $28.48 \%$ \\
\hline Sumber: Hasil pengolahan data & &
\end{tabular}

\section{Simpulan}

Probabilitas perpindahan penumpang dari kendaraan pribadi (sepeda motor dan mobil) ke angkutan umum di stasiun Madiun dengan karakteristik:

a. Karakteristik usia dalam range 1 yaitu 21-30 tahun dimana diambil sampel 25 tahun dan penghasilan dalam range 1 yaitu $\mathrm{Rp}$ 500.000-Rp 1.500.000 dimana diambil sampel di penghasilan Rp 1.000 .000 probabilitasnya sebesar $27,70 \%$.

b. Karakteristik usia dalam range 1 yaitu 21-30 tahun dimana diambil sampel 22 tahun dan penghasilan dalam range 2 yaitu Rp 1.500.000-Rp 2.500.000 dimana diambil sampel di penghasilan Rp 2.500 .000 probabilitasnya sebesar 27,50\%.

c. Karakteristik usia dalam range 1 yaitu 21-30 tahun dimana diambil sampel 28 tahun dan penghasilan dalam range 4 yaitu $>$ Rp 5.000.000 dimana diambil sampel di penghasilan $\mathrm{Rp} 7.000 .000$ probabilitasnya sebesar $27,81 \%$.

d. Karakteristik usia dalam range 3 yaitu 41-50 tahun dimana diambil sampel 45 tahun dan penghasilan dalam range 1 yaitu Rp 500.000-Rp 1.500.000 dimana diambil sampel di penghasilan Rp 1.500 .000 probabilitasnya sebesar 28,45\%.

e. Karakteristik usia dalam range 3 yaitu 41-50 tahun dimana diambil sampel 43 tahun dan penghasilan dalam 
range 2 yaitu $R p$ 1.500.000-Rp 2.500.000 dimana diambil sampel di penghasilan Rp 2.500 .000 probabilitasnya sebesar 28,41\%.

f. Karakteristik usia dalam range 3 yaitu 41-50 tahun dimana diambil sampel 49 tahun dan penghasilan dalam range 4 yaitu $>$ Rp 5.000.000 dimana diambil sampel di penghasilan Rp 10.000 .000 probabilitasnya sebesar 28,47\%.

Karakteristik yang menjadi pertimbangan untuk berpindah moda dari sepeda motor dan mobil pribadi ke angkutan umum di stasiun Madiun yaitu usia dan penghasilan. Untuk usia 1dengan range 21-30 tahun dan usia 3 dengan range 41-50 tahun. Sedangkan untuk penghasilan 1 dengan range $\mathrm{Rp} 500.000-\mathrm{Rp} 1.500 .000$, penghasilan 2 dengan range $\mathrm{Rp} 1.000 .000-\mathrm{Rp} 2.500 .000$, dan penghasilan 4 dengan range $>\operatorname{Rp} 5.000 .000$. Semakin naik usia penumpang probabilitasnya mengalami kenaikan, sedangkan semakin naik penghasilan penumpang probabilitasnya mengalami penurunan. Prosentase peluang penumpang yang menggunakan kendaraan pribadi yang kemungkinan mau berpindah menggunakan angkutan umum yaitu penumpang yang berusia lebih muda relatif tidak akan khawatir menggunakan sepeda motor dibandingkan penumpang yang berumur/berusia lanjut, sehingga peluang penumpang berumur/berusia lanjut yang menggunakan angkutan umum akan lebih besar. Demikian juga dari segi penghasilan, penumpang yang berpenghasilan tinggi akan berbeda dalam memilih moda transportasinya, penumpang berpenghasilan tinggi akan cenderung memilih menggunakan kendaraan pribadi seperti mobil dari pada menggunakan angkutan umum.

\section{Daftar Pustaka}

[1] Conor Semler dan Chris Hale, "Rail Station AccessAn Assessment of Options". Australian Transport Research Forum Conference-ITS Monash. Samler dan hale, 2010.

[2] Lilik Wachid, Nunu Lutfi, Danang Parikesit. "Kajian Indikator-indikator yang Mendasari Penyusunan Pedoman Fasilitas Perpindahan Antarmoda Perkotaan", Peneliti Pusat Studi Transportasi dan Logistik, Universitas Gajah Mada, Yogyakarta. 2006.

[3] Todd Litman, "Accessibility for Transportation Planning Measuring People's Ability to Reach Desired Goods and Activities, Evaluating Accessibility for Transportation Planning", Victoria Transport Policy Institute, 2017.

[4] Devina Octavianti, dan Hera Widyastuti, "Analisis Perpindahan Moda dari Taksi dan Mobil Pribadi ke Bus Damri di Bandar Udara Juanda Surabaya". Jurnal
Teknik ITS, vol. 1, (Sept, 2010) ISSN: 2301-9271.F.

[5] Rahmatang Rahman, "Studi Pemilihan moda Angkutan Umum Antar Kota Menggunakan Metode Stated Preference", Jurnal SMARTek, vol.7, no. 4, p.229-243, Nopember 2009.

[6] Sugiyono, Metode Penelitian Kuantitatif, Kualitatif, dan R\&D, Penerbit Alfabeta, Bandung, 2017. 
